was man durch ein gleichförmiges Nachtrupfen mittelst Regulirung des Hahus im Gefäfse $A$ bewirkt. Durch 8 Buhrlöcher am untern Theile des Fasses strömt aber ununterbrochen Luft in dasselbe, während darch die Oeffnung des Deckels das Stickgas derselben, das ja ohnehin specifisch leichter als die Luft ist, entweicht.

\title{
Ueber die Bereitung des Liquor Ammonii caustici;
}

vom

Apotheker Eduard Springmühl in Meifsen.

Vielfache Versuche und Prüfungen der bis jetzt vorgeschlagenen Methoden zur Bereitung eines guten und gleichzeitig billigen Liq. Amm. caust. liefsen mich auf die Idee kommen, mir einen eignen Apparat, von Gufseisen, wie er in beiliegender Zeichnung vorliegt, machen zu lassen, der verbunden mit Einfachheit nicht allein stets ganz reine Präparate liefert, sondern auch noch den grofsen Vortheil gewährt, dafs kein Zerspringen der Gefälse, kein Zurücksteigen der Flüssigkeiten aus den Absorptionsflaschen, noch ein Ausströmen des Gases möglich wird (vorausgesetzt, dars nur einigermafsen gut latirt ist), und dennoch bei Berechnung der geringsten dazu gehörenden Kleinigkeiten ein' billigeres Präparat liefert, als uns bis jetzt sämmtliche Fabriken liefern. Ich bereite in einem Zeitraume von 3 bis $3 \frac{1}{2}$ Stunde 58 bis 60 Pfd. Liq. Amm. caust. von chemisch reiner Beschaffenheit; doch gewirs eine kurze Zeit zur Fertigung einer solchen Menge.

Arch. d. Pharm. II. Reihe. XXVI. Bds. I. Hft. 


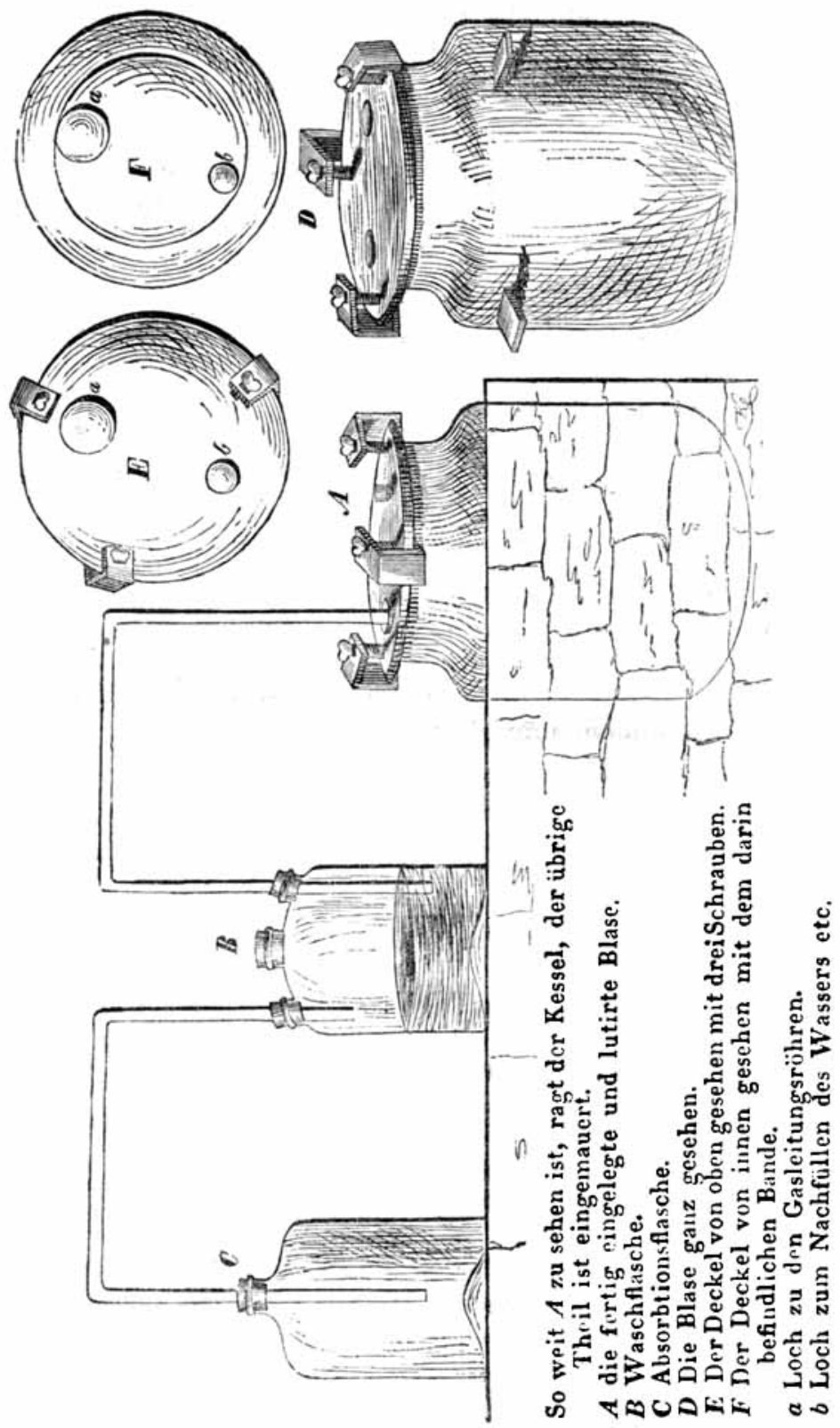


Der Hauptvortheil dieser Blase scheint mir unbedingt der zu sein, dafs in dem Deckel sich zwei Löcher befinden, das eine um die Gasleitungsröhren anzubringen, das andere, um, nachdem die Mischung aus Kalkhydrat und Salmiak in die Blase gebracht, alles lutirt, noch etwas Wasser zur Mischung gegossen werden kann, und zwar auf 12 Pfd. Salmiak ca. 4 Kannen (i 32 Unz.), so dafs ein flüssiger Brei entstelat und dadurch vorgebeuggt wird, dafs das Präparat empyreumatisch werden kann, was wohl sehr leicht geschieht, kömmt Kalkhydrat und Salmiak ohne Vasserzusatz zusammen, wie mich vielfache Erfahrungen belehrt haben. Aufserdem geht durch den Wasserzusatz die Zersetzung der Mischung weit schneller und leichter von statten, so wie ein viel geringerer Aufwand von Brennmaterial erforderlich wird, als wenn Kalk und Salmiak pulverförmig verarbeitet werden.

Fehlte dieses zweite Loch, und man wäre genöthigt, das Wasser gleich vor dem Lutiren zuzusetzen, so würde die Gasentwicklung gleich beginnen und so das Latiren nur sehr unvollkommen gelingen. Als Lutum bediene ich mich des gebrannten Gypses mit Zusatz von etwas Mehl (12 Unzen Gyps, 1 Unze Mehl) in Form eines dicken Breies, womit ich die Fugen begiefse, eben so den überstehenden hand der Blase, und dann den Deckel vermittelst dreier einfachen Schrauben befestige. Ist die Operation beundet, so öfne ich das zweite vermittelst eines Korkes verschlossene Loch, und bin nicht genöthigt, den Apparat auseinander zu nehmen, sondern kann Alles ruhig erkalten lassen, ohne dafs ein Zurücksteigen möglich ist.

Mein Apparat, der ca. 40 Kannen (à 32 Unzen) Wasser fafst, kostet etwas über 6 Thlr. und ist auf der Hütte von C. und F. Jacobi, Eisenhülte bei Meifsen, gefertigt. Sehr gern bin ich erbötig, sollte einem oder dem andern der gechrten Herren Collegen mein Apparat gefallen, die Besorgung eines solchen zu übernehmen, und würde ich dann nur um Angabe des Inhalts bitten und 
ob derselbe eingemauert oder nur auf dem Windofen benutzt werden soll, da er sich eben so bequem auf jedem beliebigen Ofen benutzen läfst.

\section{Ueber destillirte Wässer;}

\section{von}

\section{A. Monheim in Bedburg -Reifferscheidt.}

Schon lange ist es der Wunsch der Apotheker gewesen, eine Bereitungsart der destillirten Wässer zu besitzen, wodurch dieselben haltbarer werden und ihre Klarheit behalten, um des so hänfigen Filtrirens enthoben zu sein. Es ist mir endlich gelungen, einen Zusatz zu finden, wodurch nicht nur diesem Wunsche entsprochen wird, sondern wodurch sich die Wässer bedeutend in Hinsicht ihrer ätherischen Theile verbessern, so z. B. Aqua Melissae, Menthae crisp., welche bekanntlich ihre Eigenthümlichkeit durch das Alter sehr verlieren; diese werden dadurch sehr fein von Geruch und haltbar, auch haben diese Wässer, so wie die übrigen damit bereiteten, die Probe bereits über ein Jahr lang überstanden, ohne den geringsten Nachtheil zu erleiden. Bei Aqua Sambuci entwickelt sich, wegen des zu starken Ammoniakgehalts, ein geringer Antheil Ammoniak, weshalb das Wasser nicht zu fest verschlossen aufbewahrt werden darf. Ich habe diejenigen Wässer damit bereitet, welche am meisten dem Verderben unterworfen sind, als Aqua Chamomillae, Aq. Melissae, Aq. Menth. crisp., Aq. Menth. pip., Aq. Rosar. Aq. Salviae, Aq. Sambuci. Ich bediene mich nämlich eines Zusatzes von ungelöschtem Kalk und kohlensaurem Kali und nehme auf das Verhältnifs der Pharmacopoea Borussica, Editio quinta, berechnet: zwei Unzen Kalk, welchen man zuvor mit Wasser besprengt und zerfallen lärst, und dann rohes kohlensaures Kail (Pottasche) vier Unzen zusetzt, worauf die Masse mit einem Pfunde Wasser verdünnt, und nachdem sie einige Standen ruhig gestanden, in 